\title{
The cell biology of Cryptosporidium infection
}

\author{
Steven P. O'Hara ${ }^{\mathrm{a},{ }^{*}}$ and Xian-Ming Chen ${ }^{\mathrm{b}}$ \\ a Center for Basic Research in Digestive Diseases, Division of Gastroenterology and Hepatology, \\ Mayo Clinic, Rochester, Minnesota 55905 \\ b Department of Medical Microbiology and Immunology, Creighton University Medical Center, \\ Omaha, Nebraska 68178
}

\begin{abstract}
Cryptosporidiosis remains a significant cause of enteric disease worldwide. Basic investigations of host: pathogen interactions have revealed the intricate processes mediating infection. The following summarizes the interactions that mediate infection and the host responses that both permit and ultimately clear the infection.
\end{abstract}

\author{
Keywords \\ Cryptosporidium; NF-кB; Cytoskeleton; Epithelia
}

\section{Introduction}

The genus Cryptosporidium includes a group of intracellular protozoan parasites that infect epithelia. Cryptosporidium parvum was first recognized as a human pathogen in 1976 [1], nearly 70 years after the first Cryptosporidia was identified in mice [2]. For several years following its initial classification as a human pathogen, Cryptosporidium parvum was considered to be an opportunistic pathogen of significant consequence to immunocompromised individuals only. This proposition was reinforced in the early 1980's, where those individuals with AIDS frequently presented with chronic, and life-threatening cryptosporidiosis [3]. However, during this time cryptosporidiosis was also recognized as a significant causative agent of acute diarrhea in the general population, establishing cryptosporidiosis as a significant human pathogen. Subsequent large-scale outbreaks of human cryptosporidiosis, attributed to contaminated drinking water in both the UK (Swindon and Oxforshire) and USA (Milwaukee, WI) reinforced the importance of Cryptosporidium as a causative agent of acute gastroenteritis in the general population and a life-threatening disease in the immunocompromised $[4,5]$. The small intestine is the primary site of human cryptosporidiosis and extraintestinal cryptosporidiosis has been principally reported in AIDS patients with biliary cryptosporidiosis being the most common extraintestinal site of infection. The duration and severity of clinical symptoms of intestinal cryptosporidiosis depends largely upon the immune status of the infected individual. Cryptosporidiosis in the otherwise healthy individuals is usually a self-limiting illness with a

(C) 2011 Elsevier Masson SAS. All rights reserved.

Address Correspondence to: Steven P. O’Hara, Mayo Clinic, 200 First Street SW, Rochester, Minnesota 55905. Tel.: 507-284-1006; Fax: 507-284-0762; ohara.steven@ mayo.edu.

Publisher's Disclaimer: This is a PDF file of an unedited manuscript that has been accepted for publication. As a service to our customers we are providing this early version of the manuscript. The manuscript will undergo copyediting, typesetting, and review of the resulting proof before it is published in its final citable form. Please note that during the production process errors may be discovered which could affect the content, and all legal disclaimers that apply to the journal pertain. 
median duration of 9-15 days [6]. Although infection can be asymptomatic, the most common clinical manifestation is profuse watery diarrhea, containing mucus, but rarely blood or leukocytes. Other symptoms include nausea, vomiting, cramp-like abdominal pain and mild fever [6]. With the implementation of new water treatment methods, including ultraviolet irradiation and ozone treatment, transmission of waterborne pathogens has been diminished in the developed world. Furthermore, the advent of highly active anti-retroviral therapy (HAART), and subsequent restoration of immune function in HIV-infected individuals, cryptosporidiosis, in the developed world, is no longer considered life threatening. Currently, cryptosporidiosis remains a significant causative agent of acute gastroenteritis in developed countries and a major health issue for individuals with HIV/ AIDS and cause of malnutrition in children in developing countries [7].

In the early 1990's it was recognized that humans were primarily infected with two distinct types of Crypotosporidium parvum [8-10]. At the time of their discovery, these two unique C. parvum subgroups, were termed human and cattle, $\mathrm{H}$ and C, or Type 1 and Type 2.

Currently, $C$. hominis refers to the species that utilizes an infectious cycle between humans only, while $C$. parvum refers to the infective cycle involving humans and ruminants. Both $C$. parvum and $C$. hominis are acquired from contaminated water or contact with infected feces, and both remain significant worldwide causes of diarrhea. For a variety of reasons including; amenability to in vitro cell culture systems and broader host range for parasite propogation, most investigations of Cryptosporidium biology and host:parasite interactions have utilized $C$. parvum. The following review primarily focuses on the interactions between the parasite and the host epithelia. While C. parvum and C. hominis are morphologically indistinguishable, the precise mechanisms and molecules regulating host: pathogen interactions presented herein have been primarily performed using C. parvum and extrapolations to other species or genotypes should bear this in mind.

\section{Parasite life cycle and biology}

Sporulated oocysts, containing four sporozoites, are released from an infected host upon defecation. These environmentally resistant oocysts are encased in a durable oocyst wall; a complex protective barrier consisting of inner and outer oocyst walls composed of a proteinlipid-carbohydrate matrix [11]. The infective cycle begins anew when an appropriate host ingests oocysts. The infectious dose varies depending on parasite isolate, yet as few as 10 oocysts have been reported to cause disease [12]. Members of the genus Cryptosporidium complete all developmental stages in a single host (Fig. 1). C. parvum oocysts excyst in the gastrointestinal tract, releasing four motile, infective sporozoites through a suture in the oocyst wall [13]. Temperature and $\mathrm{pH}$ alone are sufficient to induce excystation [14], yet other environmental cues may include carbon dioxide, pancreatic enzymes, and bile salts [15-17]. The excystation process also likely depends on parasite derived molecules including sporozoite-associated serine and cystine proteases [18, 19], arginine aminopeptidase [20], secretory phospholipase $\mathrm{A}_{2}$ [21], and protein synthesis-associated molecules including ribosomal-associated and heat shock proteins [19]. Through a mechanism of host cell attachment and subsequent invasion, a sporozoite is encapsulated by a parasite modified host membrane $[22,23]$ to form a parasitophorous vacuole, a structure common to apicomplexans. The parasitophorous vacuole of Cryptosporidium is unique in that it remains extracytoplasmic yet is considered intracellular as it maintains its position within the host derived parasitophorous vacuole membrane on top of epithelial cells. During internalization, a unique highly invaginated membrane, the feeder organelle, forms between the parasite and host cytoplasm. Localization studies have demonstrated that at least one of the parasite-derived ATP-binding cassette containing proteins, $\mathrm{CpABC1}$, localizes to the feeder organelle and likely confers selective transport between host and parasite for nutrient uptake [24]. The trophozoite undergoes asexual reproduction by merogony forming a Type-I 
meront. Cell division results in the formation of daughter cells, each surrounded by its own membrane, while still in the mother cell in a process known as endopolygeny. Under the current paradigm of $C$. parvum development, two developmentally distinct types of meronts are formed; Type-I and Type II [25], both produce merozoites, which are morphologically similar to sporozoites [26].

It is currently proposed that eight merozoites are released from Type-I meronts when mature; these then invade neighboring enterocytes. Type-I merozoites can form another Type-I meront, effectively escalating the infection, or they can continue development with the formation of Type-II meronts. Type-II meronts undergo cell division resulting in four Type-II merozoites, each capable of infecting another enterocyte, but through unknown mechanisms are developmentally programmed to diffentiate into gametocytes to complete the sexual stage of development (Fig. 1B). Type-II merozoites ultimately produce either male or female equivalent sexual reproductive stages, microgametocytes and macrogametocytes, respectively. Up to sixteen microgametes develop within the microgametocyte. The non-flagellated microgametes, through an unknown mechanism, locate and ultimately fertilize a uninucleate macrogametocyte resulting in the only diploid stage of development. The resultant diploid zygote undergoes a process similar to meiosis (sporogony) resulting in four haploid sporozoites within an oocyst (sporulated oocyst). The formation of the protective oocyst wall is completed while the parasite is within the parasitophorous vacuole through a mechanism that is not completely understood. The resultant oocysts are either thick or thin-walled. The thick-walled oocysts are shed in the feces to await ingestion by another host, while it is proposed that the thin-walled oocysts excyst in the gut in a process of autoinfection, again escalating the infection level with the release of infective sporozoites [25].

In general, completion of this lifecycle in cell culture has proven difficult, which precludes continual passage and hinders in vitro analyses of several life cycle stages. In recent years, it was reported that propagation of $C$. parvum can occur extracellularly [27] in a manner similar to the gregarines, apicomplexan parasites of invertebrates. Interestingly, molecular phylogenetic analysis places Cryptosporidium in a clade with the gregarines that is distinct from other apicomplexans including the coccidia [28], indicating that Cryptosporidium is an early emerging branch in this phylum. The cell free culture of Cryptosporidium has not been widely adopted, likely due to difficulties in consistently reproducing these findings, and further investigations are required to define the physiological relevance of this reproductive pathway with respect to host: parasite interactions.

In recent years many advances have been made in our understanding of the evolutionary history, molecular biology, and parasite encoded metabolic pathways (Reviewed in [29]), due largely to the completed genome sequencing of both C. parvum [30] and hominis [31]. These two distinct parasites share an identical set of genes that differ by only $5 \%$ at the nucleotide level [31]. The compact genome of C. parvum ( 9.1 megabase distributed over 8 chromosomes) encodes for a streamlined metabolism lacking a mitochondrial and apicoplast genome found in other apicomplexa. Of the estimated 3,800 encoded genes, which are separated by small intergenic regions, few contain introns ( $5 \%$ of genes) [30]. Gene mapping of metabolic pathways has revealed a streamlined metabolism lacking critical enzymes for the Kreb's cycle, and therefore the parasite likely relies on glycolysis for energy. Additionally, genome analysis has revealed that the parasite lacks the capacity for the de novo synthesis of amino acids, fatty acids, and nucleosides. Therefore, it appears that Cryptosporidium relies solely on the host for nutrient acquisition and in this regard, encodes for numerous transporters that likely serve this purpose [31]. Of interest, genes encoding the machinery for RNA-mediated post-transcriptional gene silencing have not been detected $[30,32]$. Hence, not only does it appear that the parasite lacks microRNAs, which function 
as regulators of gene expression through post-transcriptional gene silencing, but siRNA technologies used to interrogate gene function will be ineffective in Cryptosporidium gene function analysis.

\section{Attachment to Host Cells}

Cryptosporidium zoites share a similar cellular organization to the zoites of other apicomplexans (Fig. 2), that is, a crescent-shaped cell with an apical complex. The parasite pellicle consists of the plasma membrane with a pair of closely apposed cytoplasmic membranes: the inner membrane complex (IMC), which forms immediately subjacent to the plasma membrane. Apicomplexan motility precedes and facilitates invasion of host cells and is dependent on attachment to a substrate. Among the apicomplexans, most proteins believed to be involved in parasite attachment to host cells and parasitophorous vacuole formation are present on the surface or exocytosed from specialized secretory vesicles of the apical complex, i.e micronemes, rhoptries, and dense granules [33]. The contents of micronemes, believed to be involved in adherence to host cells, and rhoptries, possibly involved in host cell invasion and parasitophorous vacuole membrane (PVM) formation, release their contents in a sequential manner. Dense granules likely release their contents subsequent to PVM formation and presumably modify this structure.

Following excystation, the infective sporozoites interact with the mucus lining of the small intestine. In vitro models of $C$. parvum adherence to epithelial cells demonstrated that the initial interaction between parasite and host cell was dose and time dependent and influenced by $\mathrm{pH}$ and divalent cations [34, 35]. Further investigations of the molecular mechanisms regulating Cryptosporidium adherence to host cells demonstrated that this process is mediated by carbohydrate: lectin interactions; a common molecular mechanism modulating adherence to and/or invasion of host cells by protozoon parasites. Indeed, treatment of $C$. parvum sporozoites with either glycoconjugates specific to a galactose-Nacetylgalactosamine (Gal/GalNAc)-binding lectin or, conversely, lectins specific to Gal/ GalNAc inhibited attachment [34, 36, 37], and hence internalization of the parasite. Furthermore, anti-Cryptosporidium antibodies, which recognize epitopes expressed either on the surface of infective zoites and/or localized to the apical complex of proteins, neutralize infectivity. Indeed, using this approach multiple zoite molecules have been identified that mediate adherence to host cells and thereby facilitate the initial step in the process of parasite motility and/or invasion including: gp 40 , a proteolytically processed product of the Cpgp40/15 gene which encodes both the 40kDa mucin-like glycoprotein and an antigenically distinct $15 \mathrm{kDa}$ protein, gp15 [38], which is likely processed by the recently identified Subtilase-like protease, CpSUB1 [39]; Gp900, a dominant epitope recognized by immunogloblins isolated from hyperimmune bovine colostrum collected from cows immunized with Cryptosporidium oocysts [40]; and Circumsporozoite-like glycoprotien (CSL), recognized by the mAb 3E2, which not only diminishes infection in vitro and reduces infection in a mouse model, but induces the progressive formation, posterior translocation and release of membranous precipitates from the surface of sporozoites [41]. Furthermore, in support of the reports describing parasite surface associated lectin activity, a Gal/GalNAc-specific lectin, p30, was identified by galactose-affinity chromatography and peptide sequencing. This lectin was detected in $C$. parvum and $C$. hominis, complexes with both gp900 and gp40, and the recombinant protein blocks sporozoite attachment to cultured intestinal epithelial cells. It is proposed that this lectin may form an adhesive complex, with gp900 and gp40 which mediates attachment to and invasion of epithelia [42]. Recently, the completed genome sequencing of both $C$. parvum and $C$. hominis [30, 31] has led to the identification of two additional mucin-like antigens, CpMuc4 and CpMuc5, that likely mediate attachment and invasion of epithelial cells [43]. Of interest, treatment of $C$. parvum sporozoites with either Gal/GalNAc or bovine submaxillary mucin (which contains Gal/ 
GalNAc) prior to infecting cell cultures, reduced parasite numbers observed in primary bovine epithelial cells and the human ileocecal adenocarcinoma cell line, HCT-8. However, pretreatment had no effect on the numbers of parasites that infected primary human cells [44]. Furthermore, the same treatment of $C$. hominis sporozoites had no effect on infection of HCT-8 or primary human intestinal cell cultures [44]. These observations raise the possibility that differences exist in Cryptosporidium spp. interactions with i) primary cells and cell lines, and ii) intestinal cells of different species origin, and merits further investigation. Furthermore, the $C$. parvum sporozoite protein, cp47, which localizes to the apical region of the parasite, competitively and differentially binds to various human intestinal cell lines, correlating with the efficiency of in vitro infectivity of these cells [45]. Moreover, affinity chromatography demonstrated that cp 47 interacted with a $57 \mathrm{kDa}$ protein (p57) of the host cell, which is most highly expressed in the cell line that exhibited the greatest infectivity (HCT-8), and is highly abundant in the ileum (the preferred site of infection), providing insight into the affinity of $C$. parvum for this tissue.

Apicomplexan motility and, ultimately, attachment of the apical region of the parasite with the host plasma membrane precede internalization. Apicomplexans move by substrate dependent gliding motility, a unique method of motility that is defined by the absence of any obvious modification in the shape of the moving cell. While microtubules provide structural stability and maintain polarity, the actomyosin system generates the force necessary for motility and invasion (reviewed in $[46,47])$. A mechanistic advance in understanding this mode of gliding motility and cell invasion came with observations that Toxoplasma gondii zoites relocate bound particles to their posterior pole [48]. The rate of particle translocation correlated with the observed rate of forward zoite motility and the process was inhibited by the actin depolymerizing drug cytochalasin [48]. Further observations of the Plasmodium sporozoite revealed a cytochalasin sensitive, posterior redistribution of the main surface protein, circumsporozoite protein (CSP), which was released as a trail behind the motile zoite [49]. Other Apicomplexan zoites have since showed a similar release of antigens from the posterior [50, 51] including $C$. parvum [52]. Hence, parasite antigens are translocated from the anterior to posterior pole and are released, or "shed" from the parasite in motility trails. C. parvum motility trails contain various surface associated antigens including gp15, gp40, and gp900. The sequential processes identified in gliding motility are i) secretion of adhesive molecules from the apical pole of the parasites that adhere to substrate receptors; ii) posterior translocation of the adhesive molecules; and iii) proteolytic cleavage and release of the parasite molecule in motility trails.

The involvement of microneme proteins in motility and invasion has been studied in detail for members of the Apicomplexan thrombospondin related anonymous protein (TRAP) family. The current model of TRAP-dependent gliding motility suggests that the extracellular domains of TRAP bind specifically with host cell ligands, while the C-termini interact with short actin filaments likely via aldolase (reviewed in [47]). This molecular complex is in turn translocated in the posterior direction via the parasite myosin A motor which remains fixed in position to the IMC [46]. The posterior translocation of the molecular complex propels the parasite in the forward direction. TRAPs have been identified in several genera of Apicomplexa (reviewed in [53]). The common TSP1-like domains of microneme proteins from Plasmodium spp. TRAP and TRAP related proteins [54], and Toxoplasma gondii MIC2 [55], known to play a critical role in host cell attachment and invasion, prompted the investigation into whether TSP1-like domains existed in $C$. parvum microneme proteins. Using a PCR-based approach, a putative $C$. parvum TSP family member (TRAP-C1) was amplified from genomic DNA, and identified in C. parvum $\lambda$ gt11 cDNA and genomic libraries. A single phage clone revealed a sequence with a 2,110 bp long open reading frame capable of encoding a polypeptide with multiple copies of thrombospondin 1 (TSP1) -type modules [56]. Structural features and localization of this 
protein to the apical pole suggest that it may be critical for interactions with host ligands. As many as 12 C. parvum genes have been shown to contain thrombospondin related motifs, many of which are believed to be expressed in a developmentally regulated manner [57]. Sequence analysis of TRAP members has revealed similar overall structure consisting of i) a short hydrophobic N-terminal signal sequence; ii) a region of 200 amino acids showing $40 \%$ conserved residues; iii) at least one copy of TSP1-type repeat; iv) a proline rich region; and v) a hydrophobic sequence followed by a short cytoplasmic tail. The organization of the Cterminus of the TRAP family members is highly conserved. The hydrophobic sequence most likely represents a transmembrane spanning region, which exhibits a high degree of conserved residues, while the cytoplasmic domains have a high acidic amino acid composition and possess a conserved tryptophan at the C-terminus.

\section{Invasion of Epithelia}

The ultrastructural details of sporozoite attachment and invasion are well characterized [11]. Following attachment of the parasite apical region with the lumenal surface of the host membrane, the parasite and host membranes fuse. Prior to parasite encapsulation, the intact rhoptry is in close association with the site of attachment, micronemes and dense granules migrate to the interface of parasite and host, a tunnel-like structure forms at the interface of host and parasite, and the parasite cytoplasm becomes vacuolated. As the internalization process ensues, clusters of membranous vacuoles associate with the parasite plasma membrane, and the host membrane intimately associates with these vacuoles and ultimately encapsulates the parasite [58]. Upon internalization, the zoites are internalized in a host derived, parasite modified, bi-membrane structure on the surface of epithelial cells in a unique niche that is intramembranous, yet extracytoplasmic. During the invasion process, a unique structure is formed at the base of the host-parasite interface containing electron dense material (dense band) with an adjacent polymerized actin network [59, 60]. The host-cell origin of the actin in the cytoplasm subjacent to the infection site was confirmed by forced expression of $\beta$-actin green fluorescent protein (GFP), which aggregated to a sharply circumscribed plaque of actin directly beneath the internalized parasite [60].

Based on the initial observations of filamentous actin localizing to infection sites, and the suggestion that the PVM was, at least in part, derived from host membrane, several studies focused on the recruitment of actin binding and remodeling proteins involved in dynamic host membrane protrusion events. Forney et al. [61] and Chen et al. [36] first suggested an active role for actin polymerization-dependent membrane protrusion in the establishment of infection sites on the surface of epithelial cells. In addition to the contribution of the motile force of the parasite actomyosin system, it is increasingly evident that the host actin cytoskeleton is involved in the establishment of a fully internalized zoite. Early infectivity studies, where host cells were pretreated with pharmacological inhibitors, demonstrated a role for protein tyrosine kinases and Phosphoinositol 3-Kinase (PI3K) during the invasion process [61]. It was subsequently demonstrated that $C$. parvum induced actin polymerization at sites of infection utilizing the actin branching and nucleation machinery of the Arp2/3 complex of proteins [62]. Further investigations identified multiple signaling axes that modulate actin reorganization and contribute to Cryptosporidium internalization and/or the formation of a trophozoite (Fig.3). These identified signaling axes include: PI3-kinase and the guanine exchange factor, Frabin-dependent activation of the small GTPase, CDC42 and c-Src-dependent activation of cortactin [63, 64]. More recently, it has been reported that $\mathrm{Ca}^{++}$- dependent activation of the serine/threonine Protein Kinase C (PKC) $\alpha$ and/or PKC $\beta$ contributes to $C$. parvum invasion of primary human and bovine cells and $C$. hominis invasion of primary human cells [44]. In the case of Cdc42 activation, it was demonstrated that the phosphorylation cascade culminates in N-WASP activation and recruitment/ activation of Arp2/3. 
Activation of the signaling axes driving actin reorganization likely involves a rearrangement of the epithelial membrane surface, including localized accumulation of membrane rafts as demonstrated in infected biliary epithelial cells [65]. C. parvum infection of cultured biliary epithelial cells results in the localized aggregation of ganglioside GM1, an important component of membrane rafts [65]. Moreover, membrane recruitment of ganglioside GM1 appears to be required for the subsequent activation of intracellular signals including PI3K. It was also demonstrated, using a model of $C$. parvum biliary epithelial cell infection, that the host membrane protrusion events associated with internalization are accompanied by the localized insertion, in a Myosin IIB-dependent manner [66], of the Na+/Glucose Cotransporter, SGLT1, and AQP1, a channel protein selective for the movement of water. The insertion of these channels/transporters results in localized water influx that likely accompanies the localized volume changes resulting from actin-dependent membrane protrusion [67]. Inhibition of this process, using either a pharmacological inhibitor of SGLT1, or targeted depletion of SGLT1 or AQP1, decreases infection efficiency, and, as detected by electron microscopy, diminishes the extent of membrane protrusion [67]. Of note, insertion of SGLT1 at the apical membrane of intestinal epithelial cells, and subsequent glucose uptake, is proposed to inhibit apoptotic signaling cascades induced by the intestinal parasite Giardia duodenalis [68]. Hence, Cryptosporidium infection induces cytoskeletal changes that modulate a localized actin reorganization and channel/transporter insertion, and it is likely that the signaling events initiated at the interface between host and pathogens induce whole cell, and perhaps tissue-level changes in the cytoskeletal architecture. Importantly, epithelial tight junctions are transiently disrupted during cryptosporidial infection $[69,70]$, while treatment of an intestinal epithelial cell line with TGF- $\beta 1$ inhibits $C$. parvum-induced barrier deficits [71]. The integrity of this barrier requires both protein interactions between adjacent cells and the underlying circumferential actomyosin cytoskeleton. These junctional complexes are therefore sensitive to host cell cystoskeleton modifications, perhaps initiated by the invasion process itself, or resulting from inflammatory responses that promote junctional complex disassembly. Further investigations are required to probe the significance of Cryptosporidium induced host cell cytoskeleton alterations in barrier function and pathological consequences of barrier dysfunction.

\section{Host Cell Responses to Infection}

The delicate balance between parasitism and host protective mechanisms is exemplified by the altered gene expression profile of the host. Using an array based approach, Deng et al. [72], demonstrated the altered expression of over 200 genes in infected cultured human epithelial cells. These altered genes included those associated with apoptosis, cytoskeletal dynamics, and proinflammatory signaling cascades. The inhibition or induction of epithelial cell apoptosis demonstrates the complex interaction between host and parasite. Completion of the Cryptosporidium life cycle requires viable host cells while the induction of apoptosis appears to play a host protective role by limiting parasite numbers and/or clearing the infection [73]. NF- $\mathrm{B}$ activation, in several experimental models, induces anti-apoptotic mechanisms [74, 75] and Cryptosporidium infected cells exhibit activated NF- $\kappa$ B (Fig.3), which, in turn, limits host cell death [76, 77]. Indeed, using a model of biliary cryptosporidiosis, it was demonstrated that $C$. parvum infected cells were resistant to cell death, while uninfected bystander cells underwent apoptosis in a Fas/Fas ligand-dependent manner [78]. It was further demonstrated that infected biliary epithelia resistance to cell death was NF- $\kappa \mathrm{B}$ activation dependent. C. parvum infection of intestinal epithelial cells also induces NF- $\mathrm{KB}$ signaling cascades, which ultimately regulates the expression of numerous target genes $[79,80]$. Importantly, a recent microarray-based gene expression analysis revealed that the NF- $\kappa \mathrm{B}$-regulated gene, osteoprotegerin (OPG), is upregulated in $C$. hominis and $C$. parvum infected ileal tissue explants [81]. Osteoptrotegerin, a member of the 
Tumor Necrosis Receptor superfamily, is released from intestinal epithelial cells following Cryptosporidium infection and likely functions as a soluble decoy receptor, preventing the proapototic effects of Tumor Necrosis Factor-related Apoptosis Inducing Ligand (TRAIL). This is supported by the observation that treatment of a Cryptosporidium-infected cultured intestinal cell line with TRAIL induced apoptosis and decreased parasite numbers, while the addition of recombinant OPG antagonized TRAIL-induced parasite reduction. These results demonstrate a role for TRAIL-mediated regulation of parasite viability, and reveal a novel role for OPG in modulating apoptosis during the early phase of Cryptosporidium infection [81]. While anti-apoptotic mechanisms dominate early in the infection cycle, pro-apoptotic mediators dominate the intracellular milieu later in the infection and the host cell dies [77].

The complex interaction between host and Cryptosporidium is also reflected in the regulated expression of proinflammatory mediators and eventually, clearance of infection and the termination of the inflammatory response. NF- $\mathrm{kB}$ activation, which in addition to inducing the expression of pro- and anti-apoptotic factors, also induces the expression of cytokines and chemokines. Indeed, studies using human intestinal epithelial cells and xenographs demonstrated an increased expression of multiple chemokines including CXCL-8 (Interleukin-8) [72, 79, 82], CCL5 (RANTES) [72, 82] and CXCL-10 [83]. Of these molecular cues released from intestinal epithelial cells, CXCL-10 (IFN $\gamma$-inducible protein 10 ) is known to recruit lymphocyte subsets that produce IFN $\gamma$, a critical mediator of the innate and adaptive immune responses that control cryptosporidiosis [84, 85]. The proinflammatory cytokine TNFa, a key stimulator of prostaglandin synthesis, was also detected in the lamina propria of infected volunteers [86], while infection of human intestinal cell lines and human xenografts led to the upregulation of prostaglandin HS-2, which controls the expression of prostaglandin $\mathrm{E}_{2}$ and $\mathrm{F}_{2 \alpha}$. Prostaglandin expression is significant in that these inflammatory mediators may contribute to diarrhea, and increase the production of intestinal mucin, which may act as a protective barrier to sporozoite interactions with the apical membrane of host cells. Of significant interest, Substance P expression, a neuropeptide that localizes to areas of inflammation and stimulates active Clsecretion from intestinal epithelial cells, is elevated in experimentally infected human subjects, and in AIDS patients with uncontrolled cryptosporidiosis [87]. Substance P is a critical regulator of proinflammatory cytokine expression including IL-6, TNF $\alpha$, and IFN $\gamma$ $[88,89]$. Interestingly, Cryptosporidium activation of Toll-like receptors on the surface of epithelia are required for proinflammatory mediator expression $[67,79]$ and $\beta$-defensin [90], an antimicrobial peptide that is likely cytopathic to zoites [91]. Therefore, it is likely that Toll-like receptor activation of NF- $\mathrm{BB}$ both promotes early parasite propogation, but is also a likely mechanism for the upregulation of mediators that recruit professional immune cells and, ultimately, promote parasite eradication. The latter is reinforced by the observation that mice deficient in MyD88, an adaptor protein involved in most TLR signaling pathways, exhibited greater intestinal parasite burden [92]. Interestingly, the anti-inflammatory cytokine, Transforming growth factor beta (TGF- $\beta$ ), is induced in the intestinal epithelia either during or after infection with Cryptosporidium [93] and is likely involved in tempering the inflammatory response and healing the epithelia.

In addition to transcription factor-dependent gene regulation in response to Cryptosporidium infection, microRNAs, small non-coding RNAs, have been shown to regulate gene expression. This class of recently identified non-coding RNAs post-transcriptionally regulate gene expression through complementary base-pairing to target mRNAs, and effectively limit the expression of the protein product [94]. MicroRNAs reportedly function by "fine-tuning" gene expression and are emerging as critical regulators of numerous cellular processes [95]. One of these miRNAs, let-7i, is expressed in biliary epithelial cells, and under normal cell culture conditions, targets TLR4 mRNA and post-transciptionally limits protein production [96]. However, following infection of these cultured cells with $C$. 
parvum, let-7i expression is diminished in an NF- $\mathrm{KB}$ p50-dependent manner and this process is likely involved in the epithelial defense against $C$. parvum. In this model of host cellular response to infection, pathogen recognition induces the activation of signaling cascades that not only modulate gene expression through transcription factor activation and chromatin remodeling, but ultimately repress the expression of a miRNA, which promotes upregulation of a pathogen recognition receptor; a process that may sensitize the cells to pathogen recognition and enhance signaling through this pathway [96]. Moreover, members of the mir98/let-7 family of microRNAs regulate the expression of cytokine inducible SH2 containing protein, CIS, in biliary epithelial cells following C. parvum infection [97]. Furthermore, using a miRNA-microarray approach, it has been determined that $C$. parvum infection, and gram negative $e$. coli lipopolysaccharide (LPS) distinctly alter the expression of numerous miRNA, some of which are upregulated in an NF- $\kappa B$ p65-dependent manner [98]. Hence, in addition to the cis activation or repression of defense-associated genes, the altered expression of miRNAs adds a layer of complexity to parasite-induced host gene expression, and is likely a means by which the host cell responds to and defends against microbial insults. It should also be noted that the host gene expression profile and structural/ biochemical parameters may not only be induced to eradicate the parasite, but given the success of Cryptosporidium as a human pathogen, gene expression and cellular physiological parameters are also likely altered to meet the physical and metabolic requirements of the parasite. Hence, the initial interaction between parasite and host cell initiates a series of molecular events that initially promotes parasite propagation, while inducing molecular signaling events for the elimination of the parasite, and ultimately culminates in tissue repair.

\section{Summary}

Successful parasitism by Cryptosporidium is the result of intricate interactions between the host and parasite. The process is initiated by appropriate physiological conditions of the host and the mutual expression of receptors and ligands mediating adhesion and internalization. Upon the initial interaction between parasite and host, a series of molecular events ensure an appropriate environment for the completion of the parasite life cycle, that is, the presence of viable cells which meet the metabolic needs of the developing parasite. Concurrently, the host cell recognizes an invading pathogen and responds by altering the expression of the inflammation and defense-associated genes. As a consequence of infection, the function of the host tissue is transiently affected, likely due to self-preservation attempts of the infected organism and associated attempts to clear the infection. Upon resolution of infection, the tissue is repaired and function is restored. While we have made tremendous gains in our understanding of the molecular mechanisms regulating the processes and consequences of infection our understanding of these processes is far from complete. Infection in the immunocompetent is self limited; however, infection in the immunosuppressed, including malnourished children and those with compromised cellular immunity, can be life threatening. Additionally, malnourished children are at increased risks for prolonged effects from the infection. Furthermore, the infection itself likely contributes to childhood malnourishment [99]. Young, malnourished children not only have increased risk of infection, but also suffer greater consequences compared to well-nourished children. Indeed, cryptosporidiosis in the malnourished was associated with stunting, wasting or both [99]. To date, a fully effective therapeutic option does not exist, particularly for those individuals with impaired cellular immunity. Cryptosporidium research was initially limited by the difficulty of obtaining large quantities of purified parasites and has continued to prove challenging due to the lack of methods for genetic manipulation and cryopreservation of the parasites, and the inability to propagate the parasite through asexual and sexual stages in cell culture. These limitations, coupled with the inability to obtain a synchronized population of parasites following the initial invasion process, have hampered the investigations of 
intracellular stages of parasite development. We therefore have little knowledge of the molecules and processes that drive stage specific differentiation and host processes associated with the requirements of different stages of parasite development. The complete sequencing of $C$. parvum and $C$. hominis and advances in sequencing and bioinformatic tools has rapidly advanced our understanding of basic parasite biology. These technological advances will also be essential for our understanding of species divergence, infection processes, species-specific pathology, and ultimately may promote advances in the search for a fully effective anti-Cryptosporidium therapy.

\section{References}

1. Nime FA, Burek JD, Page DL, Holscher MA, Yardley JH. Acute enterocolitis in a human being infected with the protozoan Cryptosporidium. Gastroenterology. 1976; 70:592-598. [PubMed: 815126]

2. Tyzzer EE. A sporozoan found in the peptic glands of the common mouse. Proc Soc Exp Biol Med. 1907:12-13.

3. Ma P. Cryptosporidium and the enteropathy of immune deficiency. J of Pediatr Gastroenterol Nutr. 1984:488-490. [PubMed: 6481560]

4. Mac Kenzie WR, Hoxie NJ, Proctor ME, Gradus MS, Blair KA, Peterson DE, Kazmierczak JJ, Addiss DG, Fox KR, Rose JB, et al. A massive outbreak in Milwaukee of Cryptosporidium infection transmitted through the public water supply. N Engl J Med. 1994; 331:161-167. [PubMed: 7818640]

5. Richardson AJ, Frankenberg RA, Buck AC, Selkon JB, Colbourne JS, Parsons JW, Mayon-White RT. An outbreak of waterborne cryptosporidiosis in Swindon and Oxfordshire. Epidemiol Infect. 1991; 107:485-495. [PubMed: 1752298]

6. Farthing MJ. Clinical aspects of human cryptosporidiosis. Contrib Microbiol. 2000; 6:50-74. [PubMed: 10943507]

7. Tumwine JK, Kekitiinwa A, Bakeera-Kitaka S, Ndeezi G, Downing R, Feng X, Akiyoshi DE, Tzipori S. Cryptosporidiosis and microsporidiosis in Ugandan children with persistent diarrhea with and without concurrent infection with the human immunodeficiency virus. Am J Trop Med Hyg. 2005; 73:921-925. [PubMed: 16282304]

8. Nina JM, McDonald V, Deer RM, Wright SE, Dyson DA, Chiodini PL, McAdam KP. Comparative study of the antigenic composition of oocyst isolates of Cryptosporidium parvum from different hosts. Parasite Immunol. 1992; 14:227-232. [PubMed: 1570174]

9. Ogunkolade BW, Robinson HA, McDonald V, Webster K, Evans DA. Isoenzyme variation within the genus Cryptosporidium. Parasitol Res. 1993; 79:385-388. [PubMed: 8415544]

10. Ortega YR, Sheehy RR, Cama VA, Oishi KK, Sterling CR. Restriction fragment length polymorphism analysis of Cryptosporidium parvum isolates of bovine and human origin. $\mathrm{J}$ Protozool. 38(1991):40S-41S. [PubMed: 1687825]

11. Fayer, R. General Biology. In: Fayer, R.; Xiao, L., editors. Cryptosporidium and cryptosporidiosis. CRC Press; Boca Raton: 2008. p. 1-42.

12. Okhuysen PC, Chappell CL, Crabb JH, Sterling CR, DuPont HL. Virulence of three distinct Cryptosporidium parvum isolates for healthy adults. J Infect Dis. 1999; 180:1275-1281. [PubMed: 10479158]

13. Reduker DW, Speer CA, Blixt JA. Ultrastructure of Cryptosporidium parvum oocysts and excysting sporozoites as revealed by high resolution scanning electron microscopy. The $\mathrm{J}$ Protozool. 1985; 32:708-711.

14. Hijjawi NS, Meloni BP, Morgan UM, Thompson RC. Complete development and long-term maintenance of Cryptosporidium parvum human and cattle genotypes in cell culture. Int $\mathbf{J}$ Parasitol. 2001; 31:1048-1055. [PubMed: 11429168]

15. Fayer R, Leek RG. The effects of reducing conditions, medium, $\mathrm{pH}$, temperature, and time on in vitro excystation of Cryptosporidium. J Protozool. 1984; 31:567-569. [PubMed: 6512726]

16. Reduker DW, Speer CA. Factors influencing excystation in Cryptosporidium oocysts from cattle. J Parasitol. 1985; 71:112-115. [PubMed: 2984400] 
17. Robertson LJ, Campbell AT, Smith HV. In vitro excystation of Cryptosporidium parvum. Parasitol. 1993; 106:13-19.

18. Forney JR, Yang S, Healey MC. Protease activity associated with excystation of Cryptosporidium parvum oocysts. J Parasitol. 1996; 82:889-892. [PubMed: 8973395]

19. Snelling WJ, Lin Q, Moore JE, Millar BC, Tosini F, Pozio E, Dooley JS, Lowery CJ. Proteomics analysis and protein expression during sporozoite excystation of Cryptosporidium parvum (Coccidia, Apicomplexa). Mol Cell Proteomics. 2007; 6:346-355. [PubMed: 17124246]

20. Okhuysen PC, DuPont HL, Sterling CR, Chappell CL. Arginine aminopeptidase, an integral membrane protein of the Cryptosporidium parvum sporozoite. Infect Immun. 1994; 62:46674670. [PubMed: 7927738]

21. Pollok RC, McDonald V, Kelly P, Farthing MJ. The role of Cryptosporidium parvum-derived phospholipase in intestinal epithelial cell invasion. Parasitol Res. 2003; 90:181-186. [PubMed: 12783305]

22. McDonald V, McCrossan MV, Petry F. Localization of parasite antigens in Cryptosporidium parvum-infected epithelial cells using monoclonal antibodies. Parasitol. 1995; 110:259-268.

23. O'Hara SP, Yu JR, Lin JJ. A novel Cryptosporidium parvum antigen, CP2, preferentially associates with membranous structures. Parasitol Res. 2004; 92:317-327. [PubMed: 14727189]

24. Zapata F, Perkins ME, Riojas YA, Wu TW, Le Blancq SM. The Cryptosporidium parvum ABC protein family. Mol Biochem Parasitol. 2002; 120:157-161. [PubMed: 11849715]

25. Current WL, Reese NC. A comparison of endogenous development of three isolates of Cryptosporidium in suckling mice. Journal Protozool. 1986; 33:98-108.

26. Bjorneby JM, Riggs MW, Perryman LE. Cryptosporidium parvum merozoites share neutralizationsensitive epitopes with sporozoites. J Immunol. 1990; 145:298-304. [PubMed: 2193057]

27. Hijjawi NS, Meloni BP, Ng'anzo M, Ryan UM, Olson ME, Cox PT, Monis PT, Thompson RC. Complete development of Cryptosporidium parvum in host cell-free culture. Int J Parasitol. 2004; 34:769-777. [PubMed: 15157759]

28. Carreno RA, Martin DS, Barta JR. Cryptosporidium is more closely related to the gregarines than to coccidia as shown by phylogenetic analysis of apicomplexan parasites inferred using smallsubunit ribosomal RNA gene sequences. Parasitol Res. 1999; 85:899-904. [PubMed: 10540950]

29. Zhu, G. Biochemistry. In: Fayer, R.; Xiao, L., editors. Cryptosporidium and cryptosporidiosis. CRC Press; Boca Raton: 2008. p. 57-71.

30. Abrahamsen MS, Templeton TJ, Enomoto S, Abrahante JE, Zhu G, Lancto CA, Deng M, Liu C, Widmer G, Tzipori S, Buck GA, Xu P, Bankier AT, Dear PH, Konfortov BA, Spriggs HF, Iyer L, Anantharaman V, Aravind L, Kapur V. Complete genome sequence of the apicomplexan, Cryptosporidium parvum. Science. 2004; 304:441-445. [PubMed: 15044751]

31. Xu P, Widmer G, Wang Y, Ozaki LS, Alves JM, Serrano MG, Puiu D, Manque P, Akiyoshi D, Mackey AJ, Pearson WR, Dear PH, Bankier AT, Peterson DL, Abrahamsen MS, Kapur V, Tzipori S, Buck GA. The genome of Cryptosporidium homins. Nature. 2004; 431:1107-1112. [PubMed: 15510150]

32. Rider SD Jr, Zhu G. Cryptosporidium: genomic and biochemical features. Exp Parasitol. 2010; 124:2-9. [PubMed: 19187778]

33. Soldati D, Dubremetz JF, Lebrun M. Microneme proteins: structural and functional requirements to promote adhesion and invasion by the apicomplexan parasite Toxoplasma gondii. Int J Parasitol. 2001; 31:1293-1302. [PubMed: 11566297]

34. Hamer DH, Ward H, Tzipori S, Pereira ME, Alroy JP, Keusch GT. Attachment of Cryptosporidium parvum sporozoites to MDCK cells in vitro. Infect Immun. 1994; 62:2208-2213. [PubMed: 8188342]

35. Joe A, Verdon R, Tzipori S, Keusch GT, Ward HD. Attachment of Cryptosporidium parvum sporozoites to human intestinal epithelial cells. Infect Immun. 1998; 66:3429-3432. [PubMed: 9632617]

36. Chen XM, LaRusso NF. Mechanisms of attachment and internalization of Cryptosporidium parvum to biliary and intestinal epithelial cells. Gastroenterol. 2000; 118:368-379. 
37. Joe A, Hamer DH, Kelley MA, Pereira ME, Keusch GT, Tzipori S, Ward HD. Role of a Gal/ GalNAc-specific sporozoite surface lectin in Cryptosporidium parvum-host cell interaction. J Euk Microbiol. 1994; 41:44S. [PubMed: 7804243]

38. Cevallos AM, Zhang X, Waldor MK, Jaison S, Zhou X, Tzipori S, Neutra MR, Ward HD. Molecular cloning and expression of a gene encoding Cryptosporidium parvum glycoproteins gp40 and gp15. Infect Immun. 2000; 68:4108-4116. [PubMed: 10858228]

39. Wanyiri JW, Techasintana P, O'Connor RM, Blackman MJ, Kim K, Ward HD. Role of CpSUB1, a subtilisin-like protease, in Cryptosporidium parvum infection in vitro. Eukariot Cell. 2009; 8:470477.

40. Doyle PS, Crabb J, Petersen C. Anti-Cryptosporidium parvum antibodies inhibit infectivity in vitro and in vivo. Infect Immun. 1993; 61:4079-4084. [PubMed: 8406795]

41. Riggs MW, Stone AL, Yount PA, Langer RC, Arrowood MJ, Bentley DL. Protective monoclonal antibody defines a circumsporozoite-like glycoprotein exoantigen of Cryptosporidium parvum sporozoites and merozoites. J Immunol. 1997; 158:1787-1795. [PubMed: 9029117]

42. Bhat N, Joe A, PereiraPerrin M, Ward HD. Cryptosporidium p30, a galactose/Nacetylgalactosamine-specific lectin, mediates infection in vitro. J Biol Chem. 2007; 282:3487734887. [PubMed: 17905738]

43. O'Connor RM, Burns PB, Ha-Ngoc T, Scarpato K, Khan W, Kang G, Ward H. Polymorphic mucin antigens CpMuc4 and CpMuc5 are integral to Cryptosporidium parvum infection in vitro. Eukariot cell. 2009; 8:461-469.

44. Hashim A, Mulcahy G, Bourke B, Clyne M. Interaction of Cryptosporidium homins and Cryptosporidium parvum with primary human and bovine intestinal cells. Infect Immun. 2006; 74:99-107. [PubMed: 16368962]

45. Nesterenko MV, Woods K, Upton SJ. Receptor/ligand interactions between Cryptosporidium parvum and the surface of the host cell. Biochim Biophys acta. 1999; 1454:165-173. [PubMed: 10381561]

46. Kappe SH, Buscaglia CA, Bergman LW, Coppens I, Nussenzweig V. Apicomplexan gliding motility and host cell invasion: overhauling the motor model. Trends Parasitol. 2004; 20:13-16. [PubMed: 14700584]

47. Sibley LD. Intracellular parasite invasion strategies. Science. 2004; 304:248-253. [PubMed: 15073368]

48. Dubremetz JF, Rodriguez C, Ferreira E. Toxoplasma gondii: redistribution of monoclonal antibodies on tachyzoites during host cell invasion. Exp Parasitol. 1985; 59:24-32. [PubMed: 3881269]

49. Stewart MJ, Vanderberg JP. Malaria sporozoites leave behind trails of circumsporozoite protein during gliding motility. J Protozool. 1988; 35:389-393. [PubMed: 3054075]

50. Dobrowolski JM, Sibley LD. Toxoplasma invasion of mammalian cells is powered by the actin cytoskeleton of the parasite. Cell. 1996; 84:933-939. [PubMed: 8601316]

51. Entzeroth R, Zgrzebski G, Dubremetz JF. Secretion of trials during gliding motility of Eimeria nieschulzi (Apicomplexa, Coccidia) sporozoites visualized by a monoclonal antibody and immuno-gold-silver enhancement. Parasitol Res. 1989; 76:174-175. [PubMed: 2616569]

52. Arrowood MJ, Sterling CR, Healey MC. Immunofluorescent microscopical visualization of trails left by gliding Cryptosporidium parvum sporozoites. J Parasitol. 1991; 77:315-317. [PubMed: 2010865]

53. Naitza S, Spano F, Robson KJ, Crisanti A. The Thrombospondin-related Protein Family of Apicomplexan Parasites: The Gears of the Cell Invasion Machinery. Parasitol Today. 1998; 14:479-484. [PubMed: 17040860]

54. Robson KJ, Hall JR, Jennings MW, Harris TJ, Marsh K, Newbold CI, Tate VE, Weatherall DJ. A highly conserved amino-acid sequence in thrombospondin, properdin and in proteins from sporozoites and blood stages of a human malaria parasite. Nature. 1988; 335:79-82. [PubMed: 3045563]

55. Wan KL, Carruthers VB, Sibley LD, Ajioka JW. Molecular characterisation of an expressed sequence tag locus of Toxoplasma gondii encoding the micronemal protein MIC2. Mol Biochem Parasitol. 1997; 84:203-214. [PubMed: 9084040] 
56. Spano F, Putignani L, Naitza S, Puri C, Wright S, Crisanti A. Molecular cloning and expression analysis of a Cryptosporidium parvum gene encoding a new member of the thrombospondin family. Mol Biochem Parasitol. 1998; 92:147-162. [PubMed: 9574918]

57. Deng M, Templeton TJ, London NR, Bauer C, Schroeder AA, Abrahamsen MS. Cryptosporidium parvum genes containing thrombospondin type 1 domains. Infect Immun. 2002; 70:6987-6995. [PubMed: 12438378]

58. Huang BQ, Chen XM, LaRusso NF. Cryptosporidium parvum attachment to and internalization by human biliary epithelia in vitro: a morphologic study. J Parasitol. 2004; 90:212-221. [PubMed: 15165040]

59. Bonnin A, Lapillonne A, Petrella T, Lopez J, Chaponnier C, Gabbiani G, Robine S, Dubremetz JF. Immunodetection of the microvillous cytoskeleton molecules villin and ezrin in the parasitophorous vacuole wall of Cryptosporidium parvum (Protozoa: Apicomplexa). Eur J Cell Biol. 1999; 78:794-801. [PubMed: 10604656]

60. Elliott DA, Clark DP. Cryptosporidium parvum induces host cell actin accumulation at the hostparasite interface. Infect Immun. 2000; 68:2315-2322. [PubMed: 10722635]

61. Forney JR, DeWald DB, Yang S, Speer CA, Healey MC. A role for host phosphoinositide 3-kinase and cytoskeletal remodeling during Cryptosporidium parvum infection. Infect Immun. 1999; 67:844-852. [PubMed: 9916099]

62. Elliott DA, Coleman DJ, Lane MA, May RC, Machesky LM, Clark DP. Cryptosporidium parvum infection requires host cell actin polymerization. Infect Immun. 2001; 69:5940-5942. [PubMed: 11500478]

63. Chen XM, Huang BQ, Splinter PL, Cao H, Zhu G, McNiven MA, LaRusso NF. Cryptosporidium parvum invasion of biliary epithelia requires host cell tyrosine phosphorylation of cortactin via cSrc. Gastroenterology. 2003; 125:216-228. [PubMed: 12851885]

64. Chen XM, Splinter PL, Tietz PS, Huang BQ, Billadeau DD, LaRusso NF. Phosphatidylinositol 3kinase and frabin mediate Cryptosporidium parvum cellular invasion via activation of Cdc42. J Biol Chem. 2004; 279:31671-31678. [PubMed: 15133042]

65. Nelson JB, O'Hara SP, Small AJ, Tietz PS, Choudhury AK, Pagano RE, Chen XM, LaRusso NF. Cryptosporidium parvum infects human cholangiocytes via sphingolipid-enriched membrane microdomains. Cell Microbiol. 2006; 8:1932-1945. [PubMed: 16848787]

66. O'Hara SP, Gajdos GB, Trussoni CE, Splinter PL, LaRusso NF. Cholangiocyte myosin IIB is required for localized aggregation of sodium glucose cotransporter 1 to sites of Cryptosporidium parvum cellular invasion and facilitates parasite internalization. Infect Immun. 2010; 78:29272936. [PubMed: 20457792]

67. Chen XM, O'Hara SP, Huang BQ, Splinter PL, Nelson JB, LaRusso NF. Localized glucose and water influx facilitates Cryptosporidium parvum cellular invasion by means of modulation of hostcell membrane protrusion. Proc Natl Acad Sci U S A. 2005; 102:6338-6343. [PubMed: 15851691]

68. Yu LC, Huang CY, Kuo WT, Sayer H, Turner JR, Buret AG. SGLT-1-mediated glucose uptake protects human intestinal epithelial cells against Giardia duodenalis-induced apoptosis. Int J Parasitol. 2008; 38:923-934. [PubMed: 18281046]

69. Buret AG, Chin AC, Scott KG. Infection of human and bovine epithelial cells with Cryptosporidium andersoni induces apoptosis and disrupts tight junctional ZO-1: effects of epidermal growth factor. Int J Parasitol. 2003; 33:1363-1371. [PubMed: 14527519]

70. Zhang Y, Lee B, Thompson M, Glass R, Cama RI, Figueroa D, Gilman R, Taylor D, Stephenson C. Lactulose-mannitol intestinal permeability test in children with diarrhea caused by rotavirus and Cryptosporidium. Diarrhea Working Group, Peru. J Pediat Gastroenterol Nutr. 2000; 31:16-21.

71. Roche JK, Martins CA, Cosme R, Fayer R, Guerrant RL. Transforming growth factor beta1 ameliorates intestinal epithelial barrier disruption by Cryptosporidium parvum in vitro in the absence of mucosal T lymphocytes. Infect Immun. 2000; 68:5635-5644. [PubMed: 10992464]

72. Deng M, Lancto CA, Abrahamsen MS. Cryptosporidium parvum regulation of human epithelial cell gene expression. Int J Parasitol. 2004; 34:73-82. [PubMed: 14711592]

73. Widmer G, Corey EA, Stein B, Griffiths JK, Tzipori S. Host cell apoptosis impairs Cryptosporidium parvum development in vitro. J Parasitol. 2000; 86:922-928. [PubMed: 11128511] 
74. Beg AA, Baltimore D. An essential role for NF-kappaB in preventing TNF-alpha-induced cell death. Science. 1996; 274:782-784. [PubMed: 8864118]

75. Orange JS, Levy O, Geha RS. Human disease resulting from gene mutations that interfere with appropriate nuclear factor-kappaB activation. Immunol Rev. 2005; 203:21-37. [PubMed: 15661019]

76. Chen XM, Levine SA, Tietz P, Krueger E, McNiven MA, Jefferson DM, Mahle M, LaRusso NF. Cryptosporidium parvum is cytopathic for cultured human biliary epithelia via an apoptotic mechanism. Hepatol. 1998; 28:906-913.

77. McCole DF, Eckmann L, Laurent F, Kagnoff MF. Intestinal epithelial cell apoptosis following Cryptosporidium parvum infection. Infect Immun. 2000; 68:1710-1713. [PubMed: 10678994]

78. Chen XM, Gores GJ, Paya CV, LaRusso NF. Cryptosporidium parvum induces apoptosis in biliary epithelia by a Fas/Fas ligand-dependent mechanism. Am J Physiol. 1999; 277:G599-608. [PubMed: 10484385]

79. Laurent F, Eckmann L, Savidge TC, Morgan G, Theodos C, Naciri M, Kagnoff MF. Cryptosporidium parvum infection of human intestinal epithelial cells induces the polarized secretion of C-X-C chemokines. Infect Immun. 1997; 65:5067-5073. [PubMed: 9393797]

80. Seydel KB, Zhang T, Champion GA, Fichtenbaum C, Swanson PE, Tzipori S, Griffiths JK, Stanley SL Jr. Cryptosporidium parvum infection of human intestinal xenografts in SCID mice induces production of human tumor necrosis factor alpha and interleukin-8. Infect Immun. 1998; 66:2379-2382. [PubMed: 9573136]

81. Castellanos-Gonzalez A, Yancey LS, Wang HC, Pantenburg B, Liscum KR, Lewis DE, White AC Jr. Cryptosporidium infection of human intestinal epithelial cells increases expression of osteoprotegerin: a novel mechanism for evasion of host defenses. J Infect Dis. 2008; 197:916-923. [PubMed: 18288900]

82. Maillot C, Gargala G, Delaunay A, Ducrotte P, Brasseur P, Ballet JJ, Favennec L. Cryptosporidium parvum infection stimulates the secretion of TGF-beta, IL-8 and RANTES by Caco-2 cell line. Parasitol Res. 2000; 86:947-949. [PubMed: 11133108]

83. Wang HC, Dann SM, Okhuysen PC, Lewis DE, Chappell CL, Adler DG, White AC Jr. High levels of CXCL10 are produced by intestinal epithelial cells in AIDS patients with active cryptosporidiosis but not after reconstitution of immunity. Infect Immun. 2007; 75:481-487. [PubMed: 17043107]

84. Chen W, Harp JA, Harmsen AG, Havell EA. Gamma interferon functions in resistance to Cryptosporidium parvum infection in severe combined immunodeficient mice. Infect Immun. 1993; 61:3548-3551. [PubMed: 8335387]

85. Leav BA, Yoshida M, Rogers K, Cohen S, Godiwala N, Blumberg RS, Ward H. An early intestinal mucosal source of gamma interferon is associated with resistance to and control of Cryptosporidium parvum infection in mice. Infect Immun. 2005; 73:8425-8428. [PubMed: 16299343]

86. Robinson P, Okhuysen PC, Chappell CL, Lewis DE, Shahab I, Janecki A, White AC Jr. Expression of tumor necrosis factor alpha and interleukin 1 beta in jejuna of volunteers after experimental challenge with Cryptosporidium parvum correlates with exposure but not with symptoms. Infect Immun. 2001; 69:1172-1174. [PubMed: 11160015]

87. Robinson P, Okhuysen PC, Chappell CL, Weinstock JV, Lewis DE, Actor JK, White AC Jr. Substance P expression correlates with severity of diarrhea in cryptosporidiosis. J Infect Dis. 2003; 188:290-296. [PubMed: 12854086]

88. Ansel JC, Brown JR, Payan DG, Brown MA. Substance P selectively activates TNF-alpha gene expression in murine mast cells. J Immunol. 1993; 150:4478-4485. [PubMed: 7683320]

89. Cuesta MC, Quintero L, Pons H, Suarez-Roca H. Substance P and calcitonin gene-related peptide increase IL-1 beta, IL-6 and TNF alpha secretion from human peripheral blood mononuclear cells. Neurochem Int. 2002; 40:301-306. [PubMed: 11792459]

90. Tarver AP, Clark DP, Diamond G, Russell JP, Erdjument-Bromage H, Tempst P, Cohen KS, Jones DE, Sweeney RW, Wines M, Hwang S, Bevins CL. Enteric beta-defensin: molecular cloning and characterization of a gene with inducible intestinal epithelial cell expression associated with Cryptosporidium parvum infection. Infect Immun. 1998; 66:1045-1056. [PubMed: 9488394] 
91. Chen XM, O'Hara SP, Nelson JB, Splinter PL, Small AJ, Tietz PS, Limper AH, LaRusso NF. Multiple TLRs are expressed in human cholangiocytes and mediate host epithelial defense responses to Cryptosporidium parvum via activation of NF-kappaB. J Immunol. 2005; 175:74477456. [PubMed: 16301652]

92. Rogers KA, Rogers AB, Leav BA, Sanchez A, Vannier E, Uematsu S, Akira S, Golenbock D, Ward HD. MyD88-dependent pathways mediate resistance to Cryptosporidium parvum infection in mice. Infect Immun. 2006; 74:549-556. [PubMed: 16369011]

93. Robinson P, Okhuysen PC, Chappell CL, Lewis DE, Shahab I, Lahoti S, White AC Jr. Transforming growth factor beta1 is expressed in the jejunum after experimental Cryptosporidium parvum infection in humans. Infect Immun. 2000; 68:5405-5407. [PubMed: 10948171]

94. Bartel DP. MicroRNAs: genomics, biogenesis, mechanism, and function. Cell. 2004; 116:281-297. [PubMed: 14744438]

95. Sevignani C, Calin GA, Siracusa LD, Croce CM. Mammalian microRNAs: a small world for finetuning gene expression. Mamm Genome. 2006; 17:189-202. [PubMed: 16518686]

96. Chen XM, Splinter PL, O'Hara SP, LaRusso NF. A cellular micro-RNA, let-7i, regulates Toll-like receptor 4 expression and contributes to cholangiocyte immune responses against Cryptosporidium parvum infection. J Biol Chem. 2007; 282:28929-28938. [PubMed: 17660297]

97. Hu G, Zhou R, Liu J, Gong AY, Eischeid AN, Dittman JW, Chen XM. MicroRNA-98 and let-7 confer cholangiocyte expression of cytokine-inducible Src homology 2-containing protein in response to microbial challenge. J Immunol. 2009; 183:1617-1624. [PubMed: 19592657]

98. Zhou R, Hu G, Liu J, Gong AY, Drescher KM, Chen XM. NF-kappaB p65-dependent transactivation of miRNA genes following Cryptosporidium parvum infection stimulates epithelial cell immune responses. PLoS Pathog. 2009; 5:e1000681. [PubMed: 19997496]

99. Agnew DG, Lima AA, Newman RD, Wuhib T, Moore RD, Guerrant RL, Sears CL. Cryptosporidiosis in northeastern Brazilian children: association with increased diarrhea morbidity. J Infect Dis. 1998; 177:754-760. [PubMed: 9498458] 


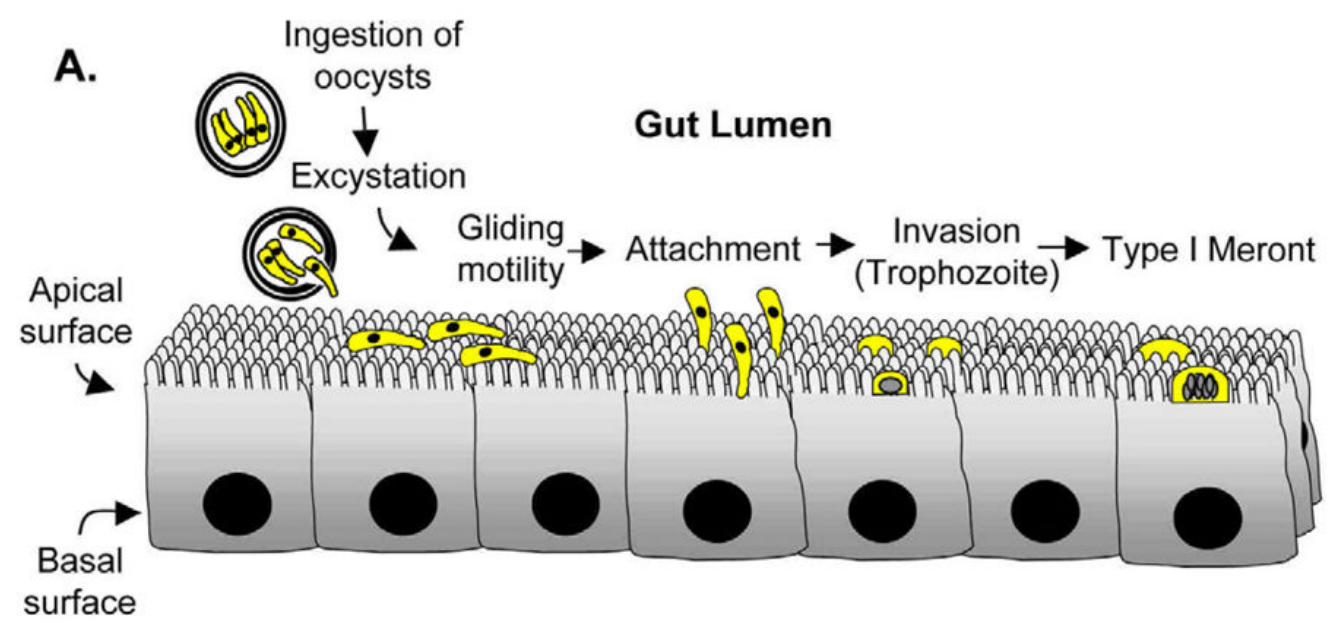

B.

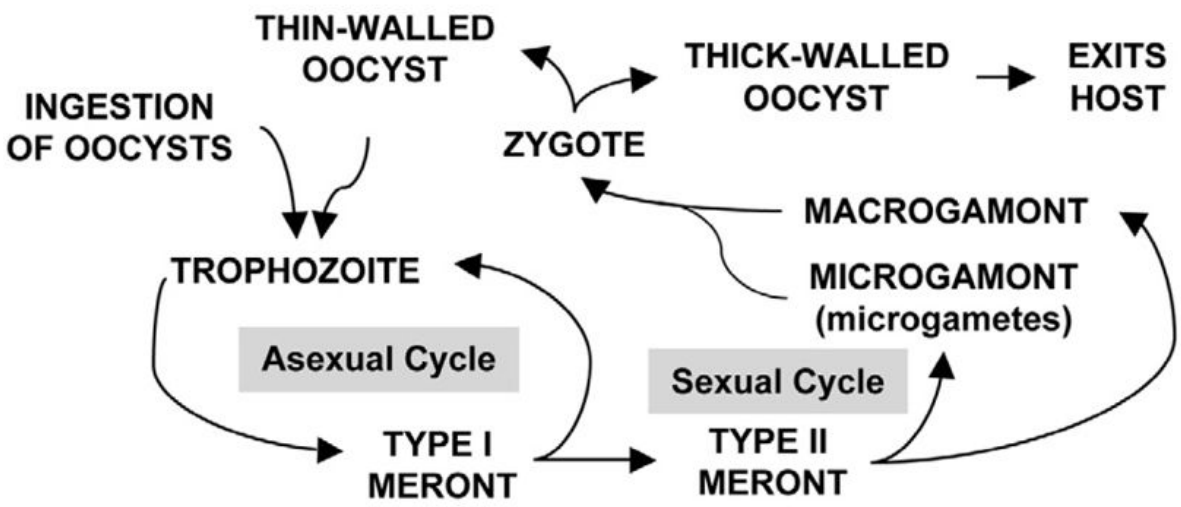

Fig. 1.

Overview of the infection process and life cycle. A. Cryptosporidiosis is initiated through the ingestion of viable oocysts, each of which contains four sporozoites. The excystation process is enhanced at $37^{\circ} \mathrm{C}$, and likely involves parasite derived enzymes. Zoite motility requires discharge of adhesive molecules from the apical complex and is temperature, $\mathrm{Ca}++$, and parasite cytoskeleton dependent. Ultimately, the apical end of the parasite attaches to the epithelial cell and initiates the internalization process. The end result of excystation, attachment, and internalization is a fully encapsulated parasite or trophozoite that develops into a Type I meront. B. Members of the genus Cryptosporidium complete all developmental stages, both sexual and asexual, in a single host. The trophozoite undergoes cell divisions resulting in 8 merozoites within a type I meront. These merozoites can re-infect the epithelium and form either a type I meront, effectively escalating the infection, or a type II meront, destined for sexual reproduction. The merozoites derived form type II meronts reinfect the epithelium and differentiate into either a micro- or macrogamont. The microgametes are released and fertilize a marogamont resulting in the only diploid stage of development, the zygote. The diploid zygote undergoes a process similar to meiosis and forms either a thin or thick walled oocyst. The former excysts in the gut lumen and re-infects the host, while the latter exits the host. 


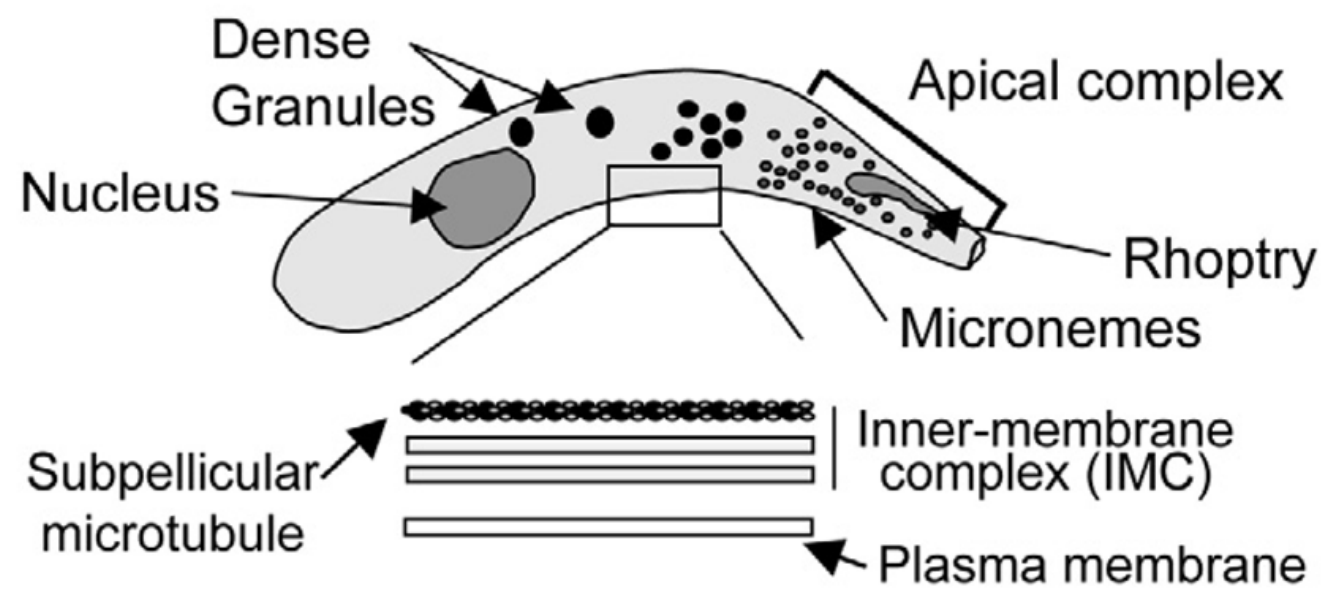

Fig. 2.

Typical zoite cellular organization. Cryptosporidium zoites share a similar body plan to other Apicomplexans including: a crescent shaped cell body; apically localized rhoptry and micronemes; and numerous dense granules throughout. The parasite pellicle consists of an outer plasma membrane and an inner membrane complex composed of 2 distinct membranes with an underlying array of subpellicular microtubules. Zoite gliding motility requires the secretion of adhesive molecules from the apical pole of the parasites (e.g. TRAP) that adhere to substrate receptors; posterior translocation of the adhesive molecules in an actomyosindependent manner; and iii) proteolytic cleavage and release of the parasite molecule in motility trails. Zoite stylized from [58]. 


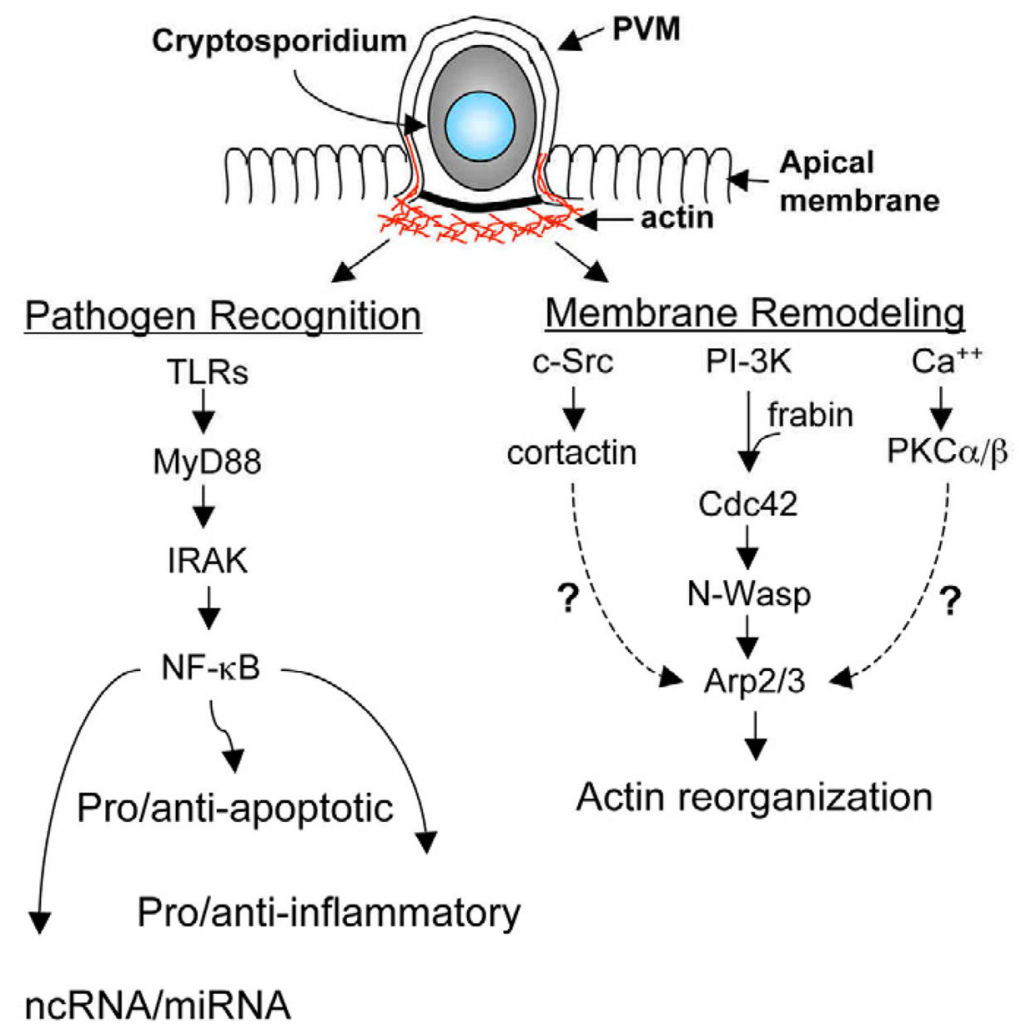

Fig. 3.

Epithelial cellular processes initiated by Cryptosporidium infection. The infection process induces epithelial responses including, activation of anti- and pro-apoptotic pathways, chemokine/cytokine secretion, modulated expression of miRNAs, and alterations of the cytoskeleton. Numerous studies have demonstrated an essential role for NF- $\mathrm{KB}$ in the host cell response to cryptosporidium infection. This transcription factor, which can be activated by Toll-like receptors, has been implicated in anti- and pro-apoptotic signaling cascades, as well as the modulated expression of proinflammatory chemokines, and miRNAs.

Additionally, the infection process induces host membrane alterations including remodeling of the host actin cytoskeleton. Multiple signaling cascades have been implicated in infection-induced actin reorganization including cortactin/c-src; PI3K/Cdc42/ARP2/3; and $\mathrm{Ca}^{++} / \mathrm{PKC} \alpha / \beta$. The host cell responses both foster early parasite development and initiate processes for parasite clearance. 